\title{
Thank You to Our Reviewers
}

The Journal of Innovations in Cardiac Rhythm Management extends sincere thanks to all reviewers who completed manuscript reviews for JICRM in 2016.

These reviewers provide high quality, rigorous, and insightful reviews of manuscripts submitted to the journal. We extend our appreciation to all reviewers for providing their expertise and time, in maintaining and enhancing the clinical relevance and scientific quality of manuscripts published in the journal. Our reviewers are instrumental to the advancement of JICRM and they greatly deserve recognition for their indispensable contributions.

Adam E. Berman

Adrian Baranchuk

Andrew Epstein

Ashish A. Bhimani

Attila Roka

Bharat K. Kantharia

Brian Dung Le

Brian Olshansky

Charles Haffajee

Charles J. Love

Christian Perzanowski

Christopher Randall Ellis

Claudio Tondo

Dario Carlos Di Toro

Gerald Naccarelli

Heather Bloom

Jason Chinitz

John D. Harding

John H. Jentzer

John Wylie

Kalyanam Skivkumar

Ken Ellenbogen

Lucas Boersma
Luna Bhatta

Macdonald Dick

Marcus Wharton

Mathew Hutchinson

Michael West

Mrinal Yadava

Olujimi Ajijola

Rahul Navin Doshi

Rakesh Gopinathannair

Raul Weiss

Ravi Mandapati

Riccardo Cappato

Richard Abben

Richard Gary Trohman

Roy John

Scott Brancato

Sergio Fabian Cossu

Sheldon Singh

Steven Bailin

Sumeet Mainigi

Tom De Potter

Vincent C. Thomas 